\title{
The biteplate facebow: a clinical and cephalometric study
}

\author{
Arnaud PEYROLADE, Rémy MATHIS, \\ Anne-Marie MUSSET
}

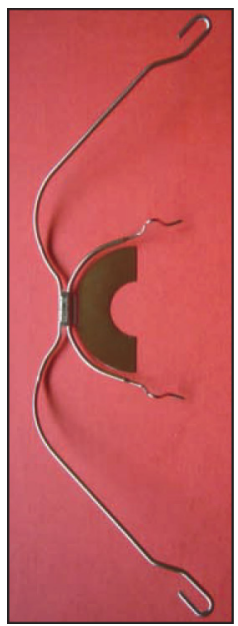

\section{ABSTRACT}

\section{Introduction}

The biteplate facebow includes a metallic occlusal plate that rests between the upper and lower incisors that is designed to correct the incisal overbite. The objective of this study is to evaluate the skeletal and dental effects of this appliance.

\section{Patients and method}

We chose thirty patients, sixteen boys and 14 girls, who had Class II malocclusions associated with a deep anterior overbite for this study. None of them had had teeth extracted as an adjunct to therapy. The only orthodontic appliance they wore was the facebow biteplate, for fourteen hours a day on the average, until their Class II molar relationship was corrected.

\section{Results}

After correction of the Class II molar relationship, we observed statistically significant before and after differences for both the incisal deep bite and the labial inclinations of the maxillary and mandibular incisors. We also noted skeletal changes at the close of treatment, notably of the mandibular plane and of point $A$, but they were not significant.

\section{Conclusion}

With this appliance, Class II Angle malocclusions with deep anterior overbites can be treated in a single stage, essentially by movements of teeth.

\section{KEYWORDS}

\section{Facebow}

Bite plate

Overbite

Class II. 


\section{1 - INTRODUCTION}

The treatment of Angle Class II malocclusions began in the $\mathrm{XIX}^{\text {th }}$ century when extra-oral appliances were first introduced. In 1865 Kingsley 24,26,28 was one of the first orthodontists to use them. He was soon followed by other practitioners including Farrar 26 , Keely ${ }^{26}$, Angle ${ }^{24,28}$, Jackson ${ }^{26}$, Case ${ }^{24,26}$. The Austrian Oppenheim ${ }^{24}$ pioneered the new era of the facebow in 1936 and in 1947 the American Kloehn ${ }^{15,24}$ reported on his use of the new appliance. In the 1960s, orthodontists first began to employ facebows associat-

\section{2 - MATERIAL AND METHOD}

\section{2 -1 - Description the appliance}

The facebow biteplate consists of an extra-oral arch and an intra-oral arch with an occlusal plate soldered to it (fig. 1).

The appliance is adjusted so that the intra-oral arch extends $3 \mathrm{~mm}$ in front of the incisal edges of the max- ed with biteplates to distalize the molars and simultaneously to relieve the anterior deep bite by intruding the maxillary incisors and/or the mandibular anteriors, according to the author's interpretation of the process (after Langlade ${ }^{17}$ ).

In view of the scant amount of information in the literature describing this appliance, we decided to evaluate its effects clinically and through a cephalometric analysis of patients with Class II malocclusions and deep anterior overbites.

illary incisors. Different sizes of the appliance are available so that the orthodontist can select one that will be suited for the patient's morphology and manner of buccal functioning. The extra-oral arch is inclined upward forming an angle of about $20^{\circ}$ with the intra-oral arch. The extra-oral arch is hooked into the neckband with large elastic bands (fig. 2 and 3).

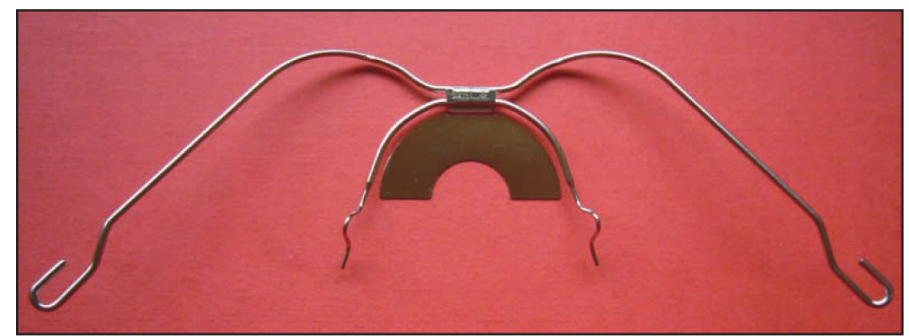

Figure 1.

Occlusal view of the appliance. 

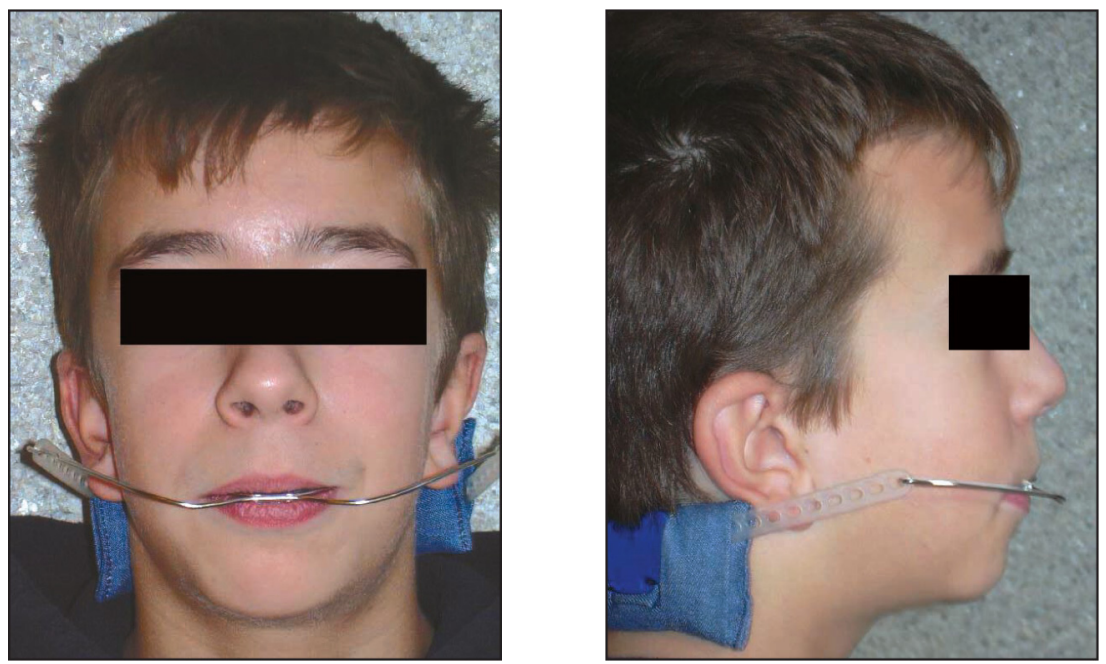

Figures 2 and 3

The appliance in place in the mouth. Full face and profile views.

\section{2 - 2 - Selection of patients}

All of the patients participating in the study had been treated in our private practice between August 2004 and June 2005 for Class II Angle malocclusions of the brachyfacial or mesiofacial type and showed anterior overbite.

None of these patients had had preliminary orthopedic dento-facial therapy and they were all treated, without extractions, by the same practitioner. They wore no appliances other than the facebow biteplate, which they were asked to use an average of 14 hours per day. We eliminated two patients who did not comply with this instruction from the study.
Thirty patients, sixteen boys and 14 girls, were included. Their average age at the beginning of treatment was 12 years and six months and 13 years and 4 months at the time a Class I molar relationship was achieved. The average length of treatment was, accordingly, 10 months, plus or minus 2 months. We took a profile cephalogram of all patients at the beginning of treatment and another one when their first molars had reached a Class I Angle condition. The same operator, using the same $X$-ray machine, took all the films.

\section{2 - 3 - Cephalometric analysis}

We employed the Ricketts cephalometric analysis for study (table I and fig. 4). 


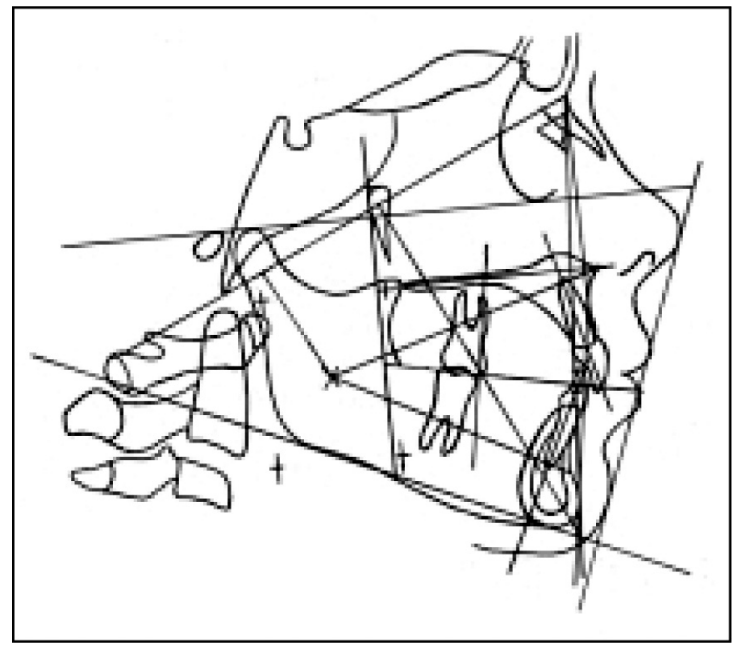

Figure 4

The Ricketts cephalometric analysis and the other measurements we used in this study.

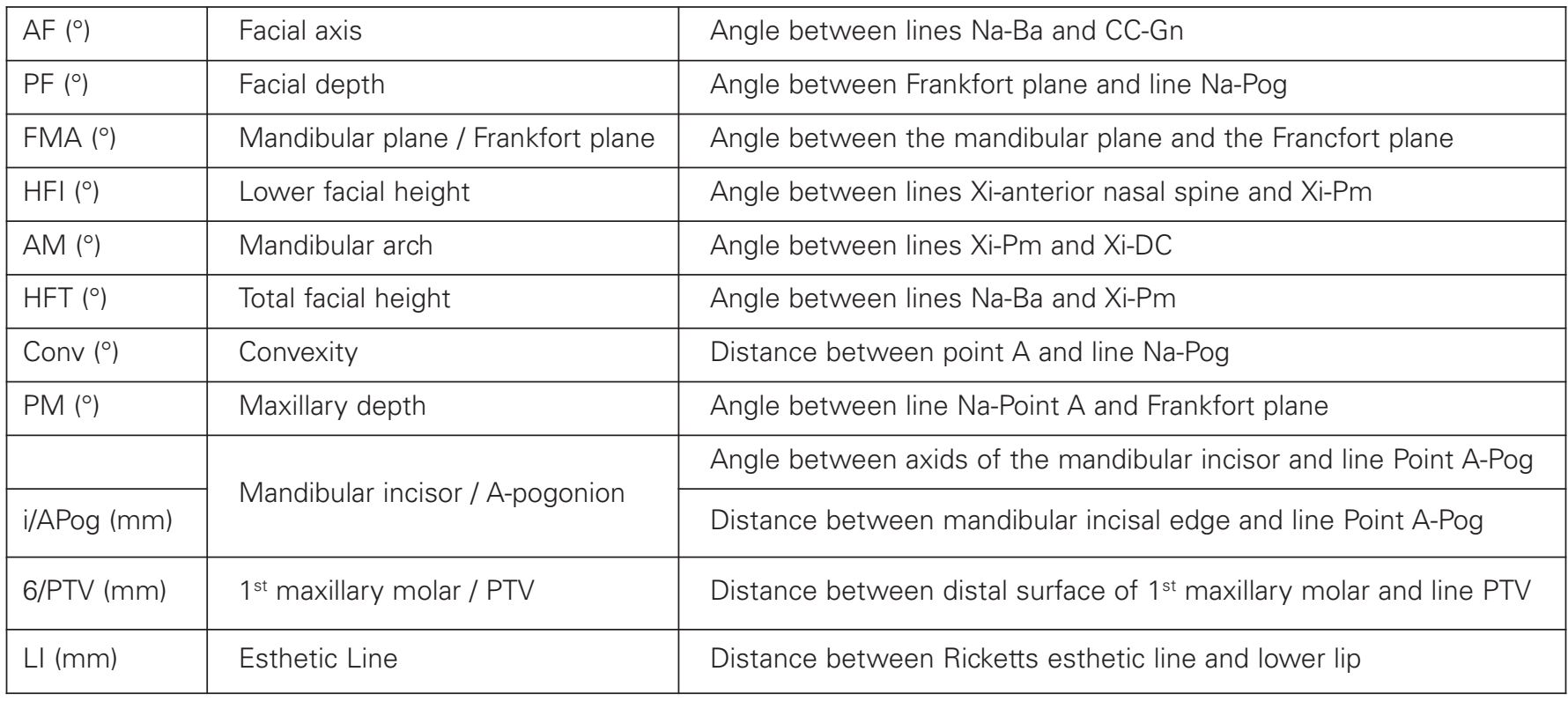

Table 1

Points and planes used in the Ricketts cephalometric analysis.

The same operator made all the tracings and all the measurements, checking them with the aid of another operator. We made supplementary measurements to this analysis (table II) that allowed us to visualize the palatal plane, the long axis of the maxillary central incisor, and the long axis of the first maxillary molar, as determined by a line connecting its mesio-buccal cusp with the apex of the mesio-buccal root as suggested by Piva ${ }^{27}$.

We made our tracings and analyses with an indelible pen on tracing sheets, the before in black and the after in red. 


\begin{tabular}{|c|c|c|}
\hline SNA $\left({ }^{\circ}\right)$ & S-Na/Na-Point A & $\begin{array}{l}\text { Angle between the S-Na plane and the line } \\
\text { Na-Point A }\end{array}$ \\
\hline $\operatorname{SNB}\left({ }^{\circ}\right)$ & S-Na/Na-Point B & $\begin{array}{l}\text { Angle between the S-Na plane and the line } \\
\text { Na-Point B }\end{array}$ \\
\hline ANB $\left({ }^{\circ}\right)$ & Na-Point A / Na-Point B & $\begin{array}{l}\text { Angle between the lines Na-Point } \mathrm{A} \text { and } \mathrm{Na}- \\
\text { Point B }\end{array}$ \\
\hline PP/PF $\left({ }^{\circ}\right)$ & Palatal plane / Frankfort plane & $\begin{array}{l}\text { Angle between the palatal plane and the } \\
\text { Frankort plane }\end{array}$ \\
\hline Overbite (mm) & Incisal overbite & $\begin{array}{l}\text { Projection of the incisal edges of the maxillary } \\
\text { and the mandibular incisors on Na-Pog }\end{array}$ \\
\hline i/PM (mm) & $\begin{array}{l}\text { Mandibular incisor / } \\
\text { mandibular plane }\end{array}$ & $\begin{array}{l}\text { Distance between the incisal edges of the } \\
\text { mandibular incisors and the mandibular plane }\end{array}$ \\
\hline I/PP $\left({ }^{\circ}\right)$ & \multirow{2}{*}{$\begin{array}{l}\text { Maxillary incisor / palatal } \\
\text { plane }\end{array}$} & $\begin{array}{l}\text { Angle between the long axis of the maxillary } \\
\text { central incisor and the palatal plane }\end{array}$ \\
\hline I/PP (mm) & & $\begin{array}{l}\text { Distance between the incisal edge of the } \\
\text { maxillary central incisor and the palatal plane }\end{array}$ \\
\hline $6 / P P\left({ }^{\circ}\right)$ & $\begin{array}{l}1^{\text {st }} \text { maxillary molar / palatal } \\
\text { plane }\end{array}$ & $\begin{array}{l}\text { Angle between the long axis of the } 1^{\text {st }} \\
\text { maxillary molar and the palatal plane }\end{array}$ \\
\hline $\mathrm{PO} / \mathrm{PM}\left({ }^{\circ}\right)$ & $\begin{array}{l}\text { Occlusal plane / mandibular } \\
\text { plane }\end{array}$ & $\begin{array}{l}\text { Angle between the occlusal plane and the } \\
\text { mandibular plane }\end{array}$ \\
\hline
\end{tabular}

Table //

The other points and planes used in the study.

\section{2 - 4 - Statistical methods}

After having completed the cephalometric analyses, we calculated the averages and the standard deviations for each variable.When we analyzed the distribution of the variables, we found it to be normal. We then compared the averages using an analysis of variance and a Student t-test. We employed Bartlett's $\mathrm{Chi}^{2}$ to test the inequality of variances: one $p$-value lower than 0.05 underlines the lack of homogeneity of the variances.

We utilized the Wilcoxon or the Mann-Whitney tests to confirm the t-test results or as substitute evaluators when the t-test could not be employed. The Wilcoxon is a non-parametric test that is comparable to the Kruskal-Wallis test for two groups. Our null hypothesis was that the averages before and after wearing the face bow with biteplate were equal $(p<0,05)$. It followed that in cases where $p$ was greater than 0.05 for a variable, we could conclude that the before-after difference between the readings was statistically significant. The tests we employed, which are often used for clinical studies $3,6,7,10,14,20,22$, are designed to allow for an evaluation of the importance of the results obtained in experiments working with small size samples like ours. 


\section{RESULTS}

The Over-all results are reported in table III. Five variables show statistically significant changes ( $p>0,05)$ :

- The angle between the mandibular incisor and the line A-Pog (i/Apog) increased $1.13^{\circ}$;
- The incisal overbite decreased $3.37 \mathrm{~mm}$;

- The angle between the long axis of the first maxillary molar and the palatal plabe (6/PP) decreased 1.10 ;

\begin{tabular}{|c|c|c|c|c|c|c|c|c|}
\hline & \multicolumn{2}{|c|}{ Before } & \multicolumn{2}{|c|}{ After } & \multirow[t]{2}{*}{ Difference Af/Be } & \multirow[t]{2}{*}{ ANOVA } & \multirow[t]{2}{*}{$\mathrm{Chi}^{2}$} & \multirow[t]{2}{*}{ Wilcoxon } \\
\hline & $\mathrm{m}$. & s.d. & $\mathrm{m}$. & s.d & & & & \\
\hline$A F\left(^{\circ}\right)$ & 88,27 & 4,41 & 87,37 & 4,76 & $-0,90$ & 0,00 & 0,50 & 0,01 \\
\hline $\operatorname{PF}\left({ }^{\circ}\right)$ & 88,33 & 2,94 & 88,67 & 3,23 & 0,33 & 0,00 & 0,26 & 0,02 \\
\hline FMA $\left(^{\circ}\right)$ & 21,13 & 5,50 & 21,87 & 5,31 & 0,73 & 0,00 & 0,80 & 0,02 \\
\hline $\mathrm{HFI}\left({ }^{\circ}\right)$ & 41,13 & 4,07 & 42,87 & 4,18 & 1,73 & 0,00 & 0,27 & 0,01 \\
\hline $\mathrm{HFT}\left({ }^{\circ}\right)$ & 56,87 & 5,28 & 57,77 & 5,46 & 0,90 & 0,00 & 0,82 & 0,05 \\
\hline $\operatorname{AM}\left({ }^{\circ}\right)$ & 34,93 & 4,32 & 35,40 & 4,86 & 0,47 & 0,00 & 0,00 & 0,02 \\
\hline Conv (mm) & 4,17 & 2,84 & 3,37 & 2,88 & $-0,80$ & 0,00 & 1,00 & 0,00 \\
\hline $\mathrm{PM}\left({ }^{\circ}\right)$ & 91,60 & 2,61 & 90,73 & 2,78 & $-0,87$ & 0,00 & 0,68 & 0,00 \\
\hline i/Apog $\left({ }^{\circ}\right)$ & 22,33 & 5,02 & 23,47 & 4,96 & 1,13 & 0,46 & 0,00 & $0,5632^{*}$ \\
\hline i/Apog (mm) & 0,37 & 2,13 & 0,80 & 2,62 & 0,43 & 0,00 & 0,05 & 0,00 \\
\hline 6/PTV (mm) & 15,40 & 4,21 & 13,93 & 4,42 & $-1,47$ & 0,00 & 0,72 & 0,03 \\
\hline LI (mm) & $-1,77$ & 3,33 & $-2,27$ & 3,23 & $-0,50$ & 0,00 & 0,10 & 0,02 \\
\hline SNA $\left({ }^{\circ}\right)$ & 82,10 & 3,78 & 81,50 & 4,04 & $-0,60$ & 0,00 & 0,14 & 0,018 \\
\hline SNB $\left({ }^{\circ}\right)$ & 77,33 & 3,67 & 77,57 & 3,99 & 0,23 & 0,00 & 0,83 & 0,015 \\
\hline ANB $\left(^{\circ}\right)$ & 4,77 & 2,50 & 3,93 & 2,64 & $-0,83$ & 0,00 & 0,71 & 0,003 \\
\hline $\mathrm{PP} / \mathrm{PF}\left({ }^{\circ}\right)$ & 2,07 & 3,36 & 1,60 & 3,59 & $-0,47$ & 0,00 & 0,16 & 0,01 \\
\hline Overbite (mm) & 6,42 & 1,35 & 3,05 & 1,85 & $-3,37$ & 0,28 & 0,01 & $0,3351^{*}$ \\
\hline i/PM (mm) & 41,93 & 3,08 & 42,47 & 2,98 & 0,53 & 0,00 & 0,94 & 0,00 \\
\hline I/PP $\left({ }^{\circ}\right)$ & 108,13 & 5,86 & 114,13 & 7,21 & 6,00 & 0,22 & 0,00 & $0,2916^{*}$ \\
\hline I/PP (mm) & 29,87 & 2,54 & 28,40 & 2,57 & $-1,47$ & 0,00 & 0,08 & 0,01 \\
\hline 6/PP $\left({ }^{\circ}\right)$ & 78,67 & 4,31 & 79,77 & 5,22 & 1,10 & 0,06 & 0,00 & $0,1259^{*}$ \\
\hline $\mathrm{PO} / \mathrm{PM}\left({ }^{\circ}\right)$ & 12,67 & 3,40 & 14,30 & 3,22 & 1,63 & 0,09 & 0,00 & $0,2943^{*}$ \\
\hline
\end{tabular}

Table III

Before and after, demonstrating results obtained in treatment $\left({ }^{*} P>0,05\right)$. 
- The incliination of the functional occlusal plane increased $1.63^{\circ}$ with respect to the mandibular plane (PO/PM).

The other variables did not display any statistically significant changes but we did observe that on the average: $0.90^{\circ}$;

- the facial axis (FA) decreased

- the facial depth (FD) increased $0.33^{\circ}$;

- the angle between the mandibular plane and the Frankfort plane (FMA) increased $0.67^{\circ}$;

- lower facial height (LFH) increased $1.73^{\circ}$ and total facial height (TFH) increased $0.90^{\circ}$;

- the mandibular arch (MA) opened $0.47^{\circ}$;

- point A (Conv) moved distally 0.80 $\mathrm{mm}$ with respect to the $\mathrm{Na}$-Pog line;

\section{4 - DISCUSSION}

\section{4 - 1 - Skeletal effects}

The facial axis (AF) decreased $0.9^{\circ}$ (fig. 5) on the average in contrast to its usual behavior of remaining stable during natural growth in untreated children (Lejoyeux ${ }^{18}$, Langlade ${ }^{17}$ ). In studies similar to ours, Chabert6 and Bacon1 both noted a decrease in the facial axis of $1.5^{\circ}$ and $1.7^{\circ}$, respectively, while Sauer ${ }^{32}$ noted an increase in this angle of $0.3^{\circ}$. From this range of data, we conclude that the appliance we used caused a modest change in this angle.

Facial depth (PF) increased $0.33^{\circ}$; this variation is comparable to the variations that occur during natural growth (Langlade ${ }^{17}$, Riolo ${ }^{31}$ ). We believe that our therapy had very little effect on facial depth. $0.87^{\circ}$

- maxillary depth (MD) decreased

- the distance between the incisal edge of the mandibular incisor and the A-Pog line (i/Apog) increased 0.43 $\mathrm{mm}$ and the distance between this incisal edge and the mandibular plane (i/PM) increased $0.53 \mathrm{~mm}$;

- the crown of the first maxillary molar (6/PTV) moved distally $1.47 \mathrm{~mm}$;

- SNA decreased $0.60^{\circ}$;

- SNB increased $0.23^{\circ}$;

- ANB decreased 0.83;

- the angle between the palatal plane and the Frankfort plane (PP/FP) decreased $0.47^{\circ}$;

- the distance between the incisal edge of the upper central incisor and the palatal plane (I/PP) decreased $1.47 \mathrm{~mm}$.

The angle between the mandibular plane and the Frankfort plane (FMA) increased $0.67^{\circ}$ while the studies of Langlade $^{17}$ and Riolo ${ }^{31}$ show that it decreases in natural growth. Gesch ${ }^{8}$, $\mathrm{Kim}^{13}$, Phan $^{25}$ and You ${ }^{35}$ found identical variations in untreated patients with Class II, division 1 malocclusions. McNamara22, Melsen ${ }^{23}$ and Ricketts ${ }^{30}$ obtained results similar to ours in their treatment of Class II patients by means of standard cervical extra-oral headgear. Our therapy caused a slight posterior rotation of the mandible (fig. 5).

Lower facial height (HFI) increased $1.70^{\circ}$ (fig. 6) in the patients in our study while it remains stable during natural growth ${ }^{6,17}$. Chabert ${ }^{6}$ and Sauer $^{32}$ noted the same effect in their studies. Total facial height (HFT), 
which remains stable in natural growth (Béry ${ }^{2}$ ), increased $0.90^{\circ}$ during treatment. This therapeutic effect is also found when extra-oral force is used without a biteplate. The two variations are probably correlated to a slight posterior rotation of the mandible and, to a lesser extent, to a tilting of the maxilla.

The mandibular arch (AM) opened $0.47^{\circ}$ (fig. 6), which is the same order of change that occurs in natural growth (Chabert ${ }^{6}$, Langlade ${ }^{17}$ ).

Convexity (conv) decreased 0.8 $\mathrm{mm}$ during treatment (fig. 5). Point $A$ usually moves distally in natural growth (Langlade ${ }^{17}$, Riolo ${ }^{31}$ ) but seems to move forward in Class II malocclusions $3,78,29,35$. Other studies $^{3,714,19,22,23,30}$ have shown an inhibition of maxillary growth in patients treated with cervical extra oral force. Our therapy did seem to influence the position of point $A$, causing it to move distally.

Maxillary depth (PM) decreased $0.87^{\circ}$, which is probably associated with the retreat of point $A$ (fig. 5). According to Riolo ${ }^{31}$, this angle normally increases with age in girls $10.6^{\circ}$ per year between the ages of 10 to 14) and remains stable in boys until they reach the age of 13 when this angle decreases $0.8^{\circ}$ and then increases later. You ${ }^{35}$ demonstrated an average increase of $1.69^{\circ}$ of this measurement between the ages of 9 to 18 years in untreated patients with Class II malocclusions. Sauer ${ }^{32}$ reported an average increase of this angle of $0.4^{\circ}$ during treatment, demonstrating the extra oral force's inhibiting action on the advance of point $A$. In the same way, the face bow with a biteplate not only prevented forward movement of point A but also actually moved it backward.

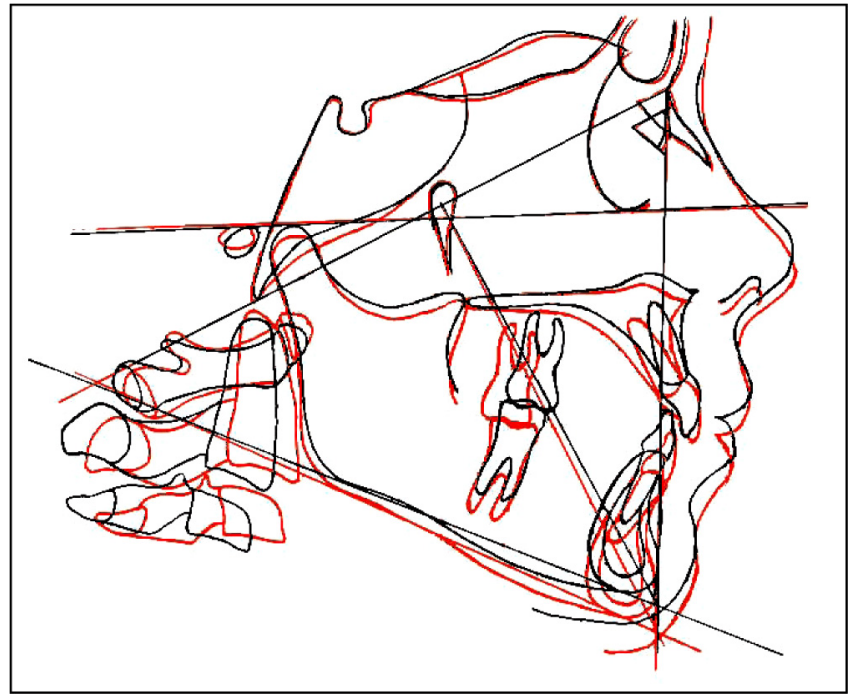

Figure 5

Superimposition of the tracings on the Ba-Na axis centered on CC, which gives a good view of the changes obtained in the maxilla and in the mandible.

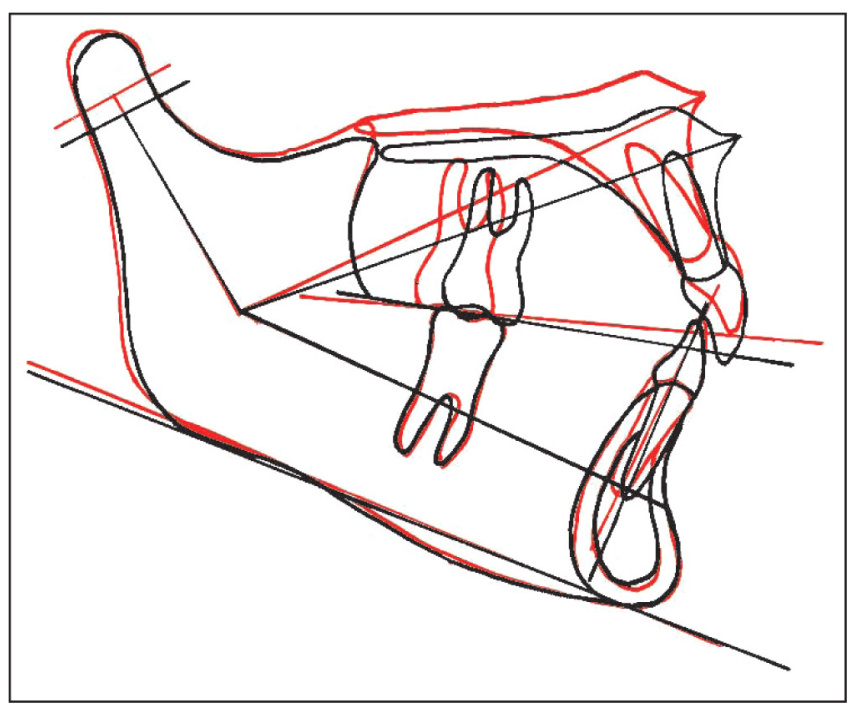

Figure 6

Local superimposition of the mandible on the Xi-Pm axis centered on Pm. This gives a good view of the labial tipping of the mandibular central incisor, the increase in lower facial height, and of the change in the orientation of the functional occlusal plane. 
The SNA angle decreased $0.6^{\circ}$ in our study. According to Riolo ${ }^{31}$, this angle increases during natural growth in boys between the ages of 12 to 13 and decreases $0.4^{\circ}$ in girls during the same period. Patients with untreated Class II, division 1 malocclusions had an increase of this angle between the ages of 8 to 12 according to Bishara ${ }^{4}$, between 12 to 14 according to, Phan ${ }^{25}$, between 11 to 13 according to Lux ${ }^{20}$, between 9 to 12 according to Ramos $^{29}$, and between 10 and 12 according to Müller (cited by Gesch $^{8}$ ) and Gesch ${ }^{8}$. Lux ${ }^{20}$ noted the same changes in patients with untreated Class II, division 2 malocclusions. Studies focused on patients who wore tradition extraoral arches $3,11,14,19,25,33$ also reported a reduction of the value of the SNA angle ranging from $0.6^{\circ}$ to $3^{\circ}$. Sauer ${ }^{32}$, who used extra oral force with a biteplate obtained results similar to ours $\left(0.3^{\circ}\right)$. Our appliance confirmed the therapeutic effect he reported of a retreat of point $A$.

We observed a slight increase of the SNB angle of $0.23^{\circ}$, which, according to Riolo ${ }^{31}$ continues to increase during the course of natural growth. Studies dealing with patients with untreated Class II malocclusions derived the same findings $4,8,20,25,29$. Sauer ${ }^{32}$ found the same tendency. All this data suggests our appliance had no effect on the advancement of point $B$.

We noted a decrease in ANB of $0.83^{\circ}$ in both girls and boys. Riolo ${ }^{31}$ reported an average decrease of this angle of $0.2^{\circ}$ in the natural growth of children 12 to 13 years of age. Some authors, Phan ${ }^{25}$, Ramos ${ }^{29}$, Müller and Janson cited by Gesch ${ }^{8}$, Gesch ${ }^{8}$, and LuX ${ }^{20}$ have observed a decrease in this angle with natural growth in children with untreated Class II malocclusions; but Bishara ${ }^{4}$ found an increase in boy and a decrease in girls. You ${ }^{35}$ noted a decrease in this angle of $1.03^{\circ}$ in untreated children between 8 and 18 with Class II, division 1 malocclusions. Sauer ${ }^{32}$ obtained an average decrease of this angle of $1^{\circ}$. This phenomenon is probably associated with a decrease in angle SNA and a slight increase in SNB, from which information we can deduce that our therapy had an indirect effect on this parameter.

The palatal lane (PP/PF) tipped in a clockwise direction, which confirms the results of Chabert $^{6}$ and Sauer ${ }^{32}$ (fig. 5). This plane descends parallel to itself in the course of natural growth ${ }^{17}$. For untreated children with Class II, division 1 malocclusions, Mäntysaari ${ }^{21}$ observed that the plane was stable but $\mathrm{Kim}^{13}$ and Dubois ${ }^{7}$ stated that it rotated counter-clockwise. On the other hand, many studies devoted to patients with Class II, division 1 malocclusions treated with cervical extra-oral force assert that the maxilla rotated in a clockwise

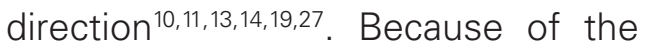
weak variation, $0.47^{\circ}$, in this variable $\mathrm{n}$ our findings, we cannot attribute this movement to the action of our appliance.

\section{4 - 2 - Behavior of the functional plane of occlusion}

The angle between the functional plane of occlusion and the mandibular plane increased a statistically significant average of $1.63^{\circ}$, rising from $12.67^{\circ}$ to $14.3^{\circ}$, which reflects a counter-clockwise tilting of the functional plane of occlusion (fig. 6). In her 
study, Kuntz ${ }^{16}$ reported that the average value of this angle was $15.3^{\circ}$ in patients who had a Class I occlusion and $13.5^{\circ}$ in patients with Class II, division 1 malocclusions. Our therapy tended to provide treated patients with an orientation of the functional plane of occlusion close to that found in Class I patients.

\section{4 - 3 - Dento-alveolar effects}

We observed a statistically significant labial inclination of the mandibular central incisor (i/Apog), which was clearly a reaction to the orthodontic action of the appliance (fig. 6) because in the absence of treatment the inclination of this tooth is stable during the growth period ${ }^{1731}$. We also noted that the distance between the incisal edge of this tooth and the mandibular plane (i/PM) increase and average of $0.53 \mathrm{~mm}, 0.44 \mathrm{~mm}$ for boys and $0.64 \mathrm{~mm}$ for girls. According to Riolo ${ }^{31}$, this measurement increases $1 \mathrm{~mm}$ per year between the ages of 10 to 15 in boys and $0.5 \mathrm{~mm}$ per year between 10 and 12 years and 1 $\mathrm{mm}$ from 12 to 13 in girls during natural growth. The smaller augmentation of the distance between the incisal edge and the mandibular plane occurring in our study would result from its labial tilting and an inhibition of its extrusion.

We found that the incisal overbite was reduced a statistically significant $3.37 \mathrm{~mm}$. In untreated Class II, division 1 patients Bishara ${ }^{4}$, Mäntysaari21 and $\mathrm{You}^{35}$ reported that the overbite increased, $\mathrm{Kim}^{13}$ asserted that it remained stable, and $\operatorname{Phan}^{25}$ derived data that demonstrated a decrease. Bondemark $^{5}$ noted a $0.70 \mathrm{~mm}$ decrease in overbite in patients treated with extra-oral force without a biteplate. Sauer ${ }^{32}$ also obtained a statistically significant decrease of overbite in a study similar to ours. The considerable improvement in overbite that we achieved would clearly seem to be caused by the effect of the extraoral force and the biteplate, which also, at least in part, provoke the buccal tilting of the incisors and the slight posterior rotation of the mandible.

Our data show a statistically significant buccal inclination of the maxillary central incisor (I/PP) of $6^{\circ}$ (fig. 8 and 9). In natural growth, according to Riolo ${ }^{31}$ and You $^{35}$, this tooth remains stable and un-tilted. We noted a decrease in the distance between the incisal edge of the maxillary central incisor and the palatal plane of $1.47 \mathrm{~mm}$ while this distance increases in natural growth (Riolo $\left.{ }^{31}\right)$. It appeared that the biteplate induced a buccal tilting of this tooth that was accompanied by a moderate intrusion of this tooth.

The long axis of the maxillary first molar (6/PP) rotated a statistically significant $1,1^{\circ}$ (fig. 8), a movement that was associated with the inclinaison of the extra-oral arch of the facebow. This result confirmed the data reported in the literature ${ }^{9,11,12,2734}$. We noted that the first maxillary molar of our patients moved distally (6/PTV). However, in the course of undisturbed natural growth, this tooth migrates mesially $1 \mathrm{~mm}$ per year according to Langlade ${ }^{17}$; other researchers have reported the same process in untreated patients who had Class II malocclusions ${ }^{78,28,35}$. Other authors whose patients wore cervical headgear without a biteplate have reported results similar to ours $5,9,12,23,31,34$. So it can be concluded that extra-oral force, employed with or without a biteplate, stimulates distal movement of the first maxillary molar (fig. 6, 7, 8, 9). 
a
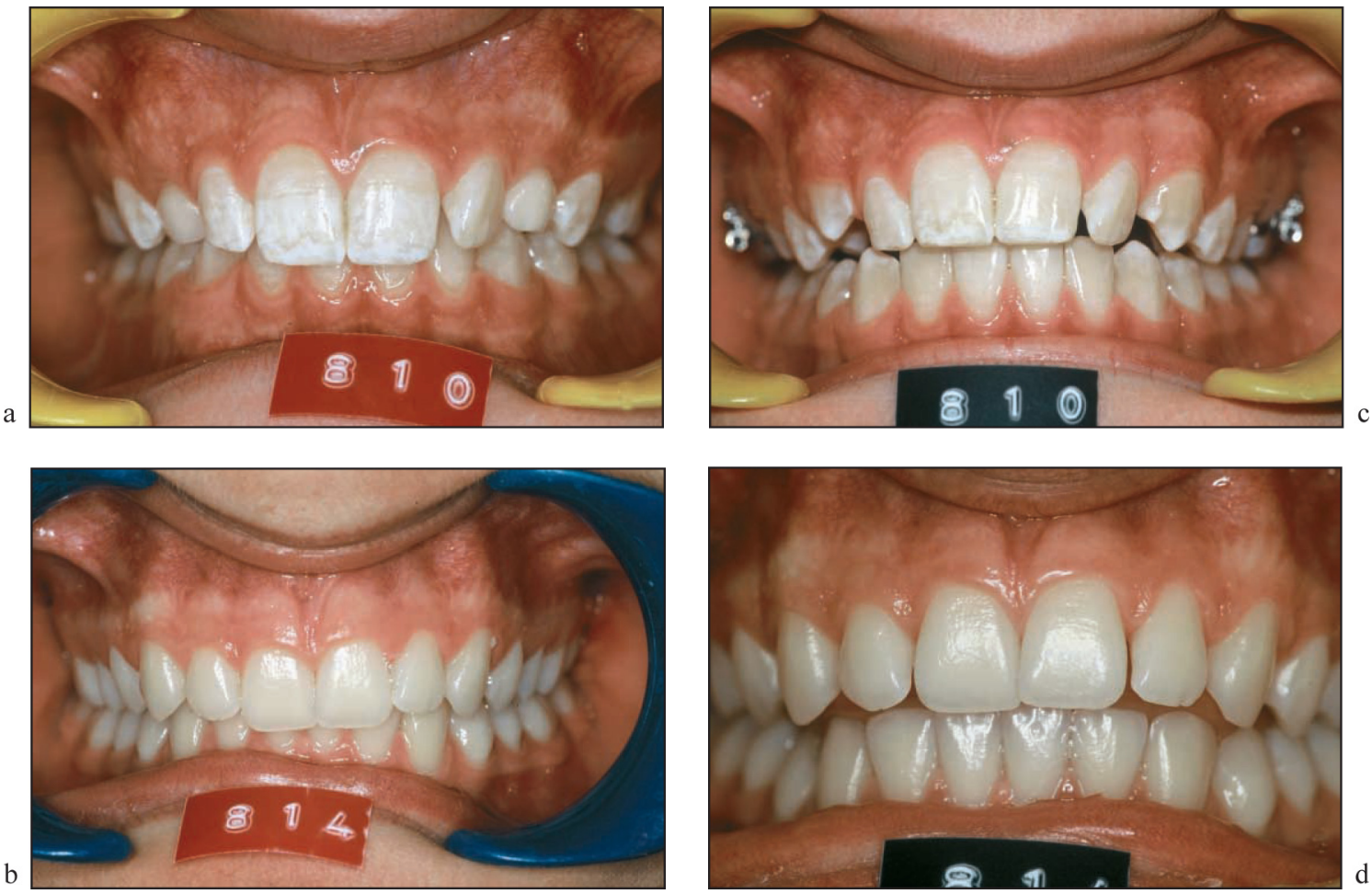

Figures 7 a to $d$

$a$ and b: initial incisal overbite;

$c$ and $d$ : result at the end of wearing the extra-oral force.

\section{4 - 4 - Perspectives}

From the results of this study, we can conclude that extra-oral force delivered from cervical anchorage in association with a bite- plate is an effective apparatus for correcting both a Class II molar relationship and an incisal overbite. Overall, we found in analyzing our results that we achieved effects similar to those gained in traditional cervical extra-oral treatment such as closing of the facial axis, posterior rotation of the mandible, and distal movement of point $A$. Dentally, we observed a distaliza- tion of the upper first molar similar to what has been reported in studies of traditional treatment and, in addition, we obtained a correction of the incisal overbite thanks to the action of the biteplate.

The opening of the bite allowed us, in a second stage of treatment to immediately install a full-banded appliance on most of the patients who had benefited from the facebow bite plate therapy (fig. 10), a procedure that is less often possible for patients who received extra-oral traction without a biteplate and, accordingly, had no reduction of the anterior deep bite. 


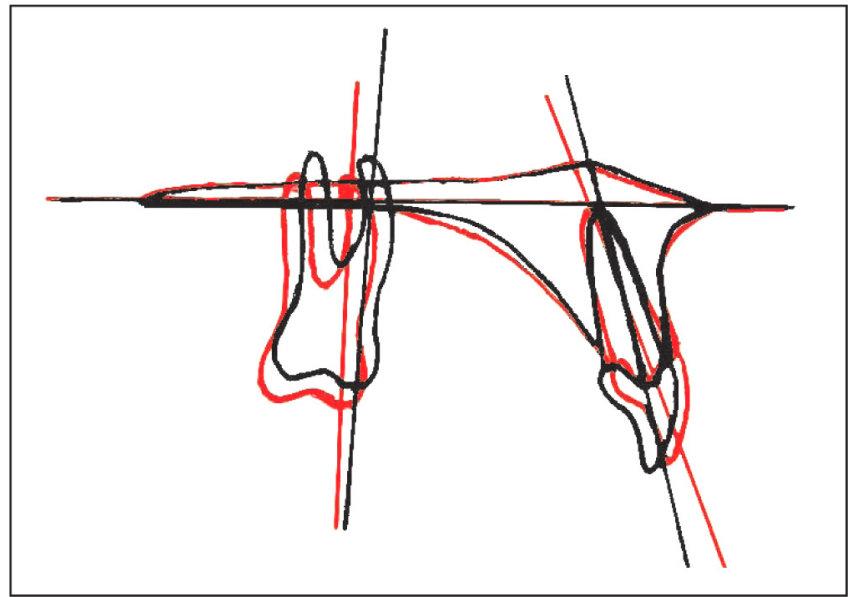

Figure 8

Local superimposition of the maxilla on the palatal plane centered on the anterior nasal spine. This gives a good view of the labial tipping of the maxillary central incisor, and the distal movement and mesial inclination of the upper first molar.
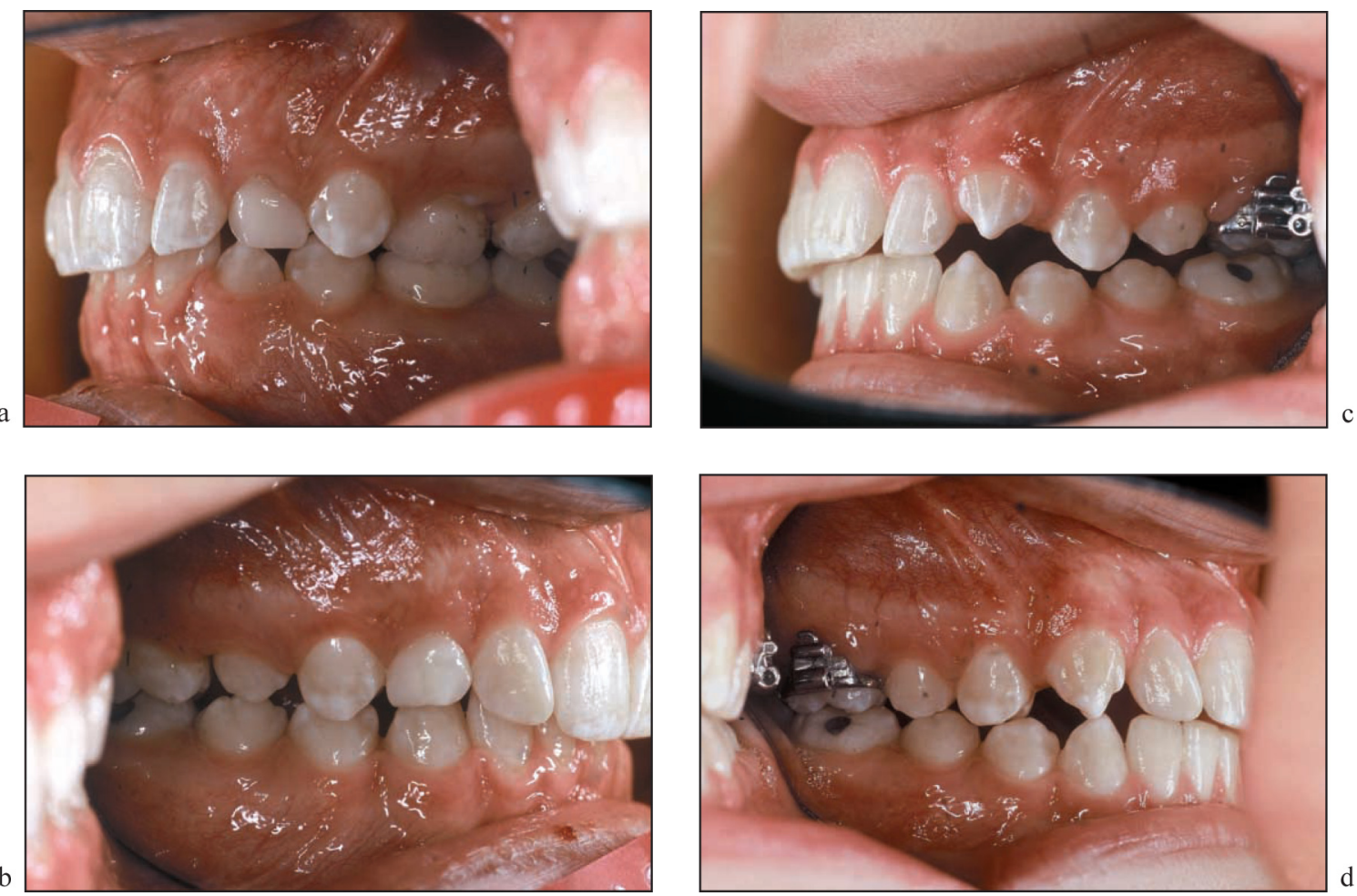

Figures 9 a to $d$

$a$ and b: initial clinical condition;

$c$ and $d$ : clinical status at the end of wearing extra-oral force: the maxillary first molars are in Class I, the overbite has been eliminated, and the maxillary central incisors have been tipped labially. 

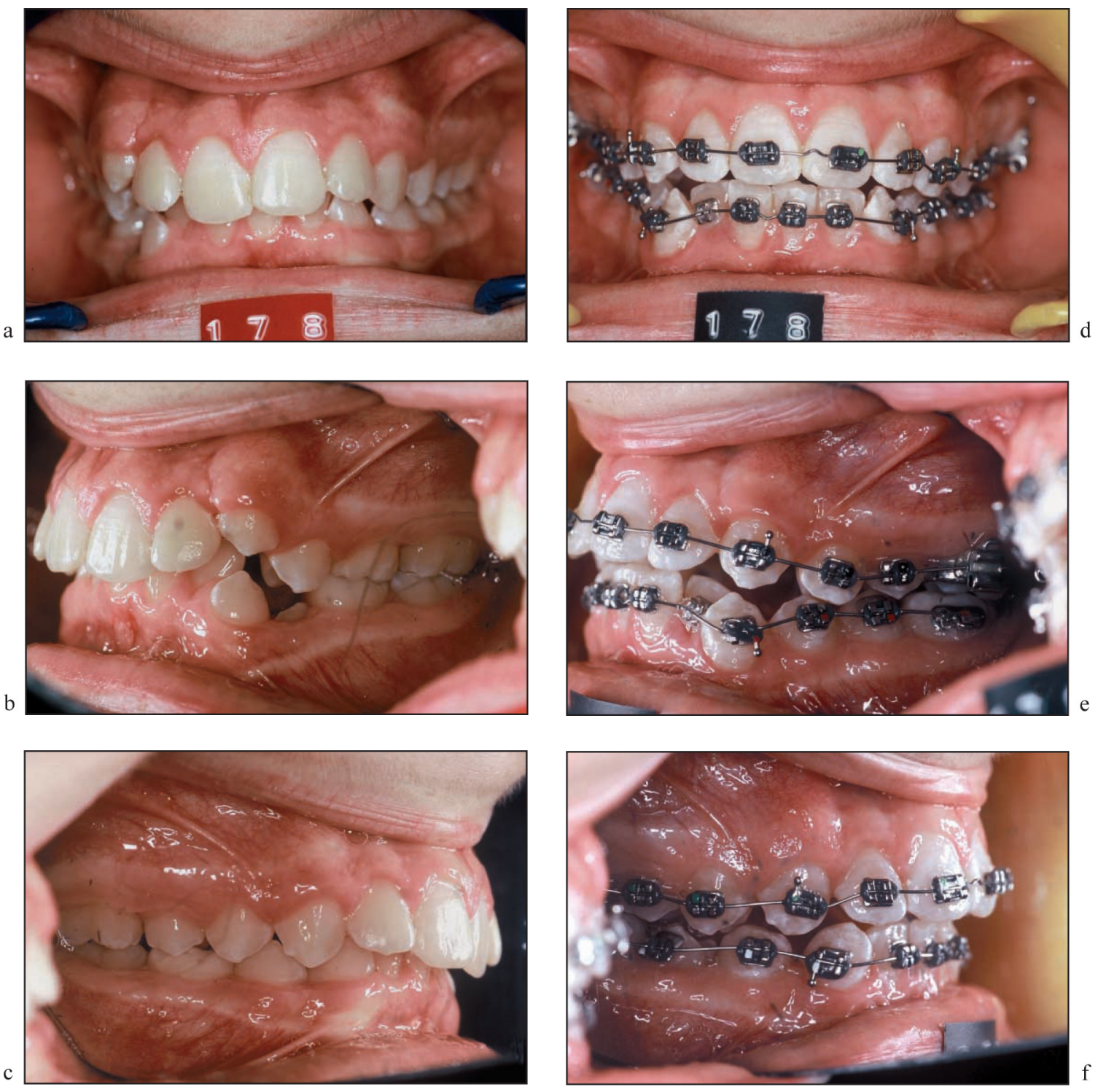

Figures 10 a to $f$

a to c: initial clinical condition;

$d$ to f: Clinical status after wearing the appliance: the maxillary and mandibular arches have been fully bonded and banded in a single appointment.

\section{5 - CONCLUSION}

We made a cephalometric evaluation of the changes produced by the wearing of cervical extra-oral force with a biteplate in thirty patients who had begun treatment with a Class II malocclusion and anterior overbite.

The skeletal effects we obtained, such as the distal movement of point $A$, 
the decrease in convexity, the increase in facial height or the posterior rotation of the mandible, conformed to the results reported by the majority of authors 3,67 14, 19, 22, 23, 30. The same was true of the distal movement of the first maxillary molar ${ }^{5}, 9$ 12, 23, 30, 34 .

But, in addition, we also obtained important changes of the incisors. We observed a statistically significant reduction of the anterior overbite, which resulted from a statistically significant labial tipping of the incisors and also from the intrusion force of the biteplate component of our appliance.

The facebow with biteplate can, therefore, be considered a reliable appliance for the correction of a Class II molar relationship as well as for eliminating an anterior overbite. It certainly seems indicated for the treatment of Class II Angle malocclusions of the brachyfacial or mesiofacial type associated with a deep anterior overbite.

\section{REFERENCES}

1. Bacon W, Lacoste, JL. La traction extra-orale de Cervera. Rev Odontostomatol 1978;7:423-6.

2. Béry J, Béry A, Garcia R. F.E.O. sur gouttière. Rev Ortho Dento Faciale 1992;26:20514.

3. Bishara SE, Zaher AR, Cummins DM, Jakobsen JR. Effect of orthodontic treatment on the growth of individuals with class II, division 1 malocclusion. Angle Orthod 1994;64:221-30.

4. Bishara SE, Jakobsen JR, Vorhies B, Bayati P. Changes in dentofacial structures in untreated Class II, division 1 and normal subjects: A longitudinal evaluation. Angle Orthod 1997;67:55-66.

5. Bondemark L, Karlsson I. Extraoral vs intraoral appliance for distal movement of maxillary first molars: a randomized control trial. Angle Orthod 2005;75:699-706.

6. Chabert G. Etude céphalométrique des effets orthopédiques et orthodontiques de I'arc facial «Equi C» de Cervera. Orthod Fr 1995;66:347-68.

7. Dubois G, Bacon W, Turlot JC. Forces extra-orales cervicales et modifications maxillomandibulaires: étude statistique. Rev Orthop Dento Faciale 1981;15:253-63.

8. Gesch D. A longitudinal study on growth in untreated children with Angle Class II, Division 1 malocclusion. J Orofac Orthop 2000;61:20-33.

9. Greenspan, R. A. Reference charts for controlled extraoral force application to maxillary molars. Am J Orthod Dentofac Orthop 1970;58:486-91.

10. Haas AJ. Headgear therapy: the most efficient way to distalize molars. Sem Orthod 2000;6:79-90.

11. Hubbard GW, Nanda RS, Currier GF. A cephalometric evaluation of nonextraction cervical headgear treatment in Class II malocclusions. Angle Orthod 1994;64:359-70.

12. Jacobson A. A key to the understanding of extraoral forces. Am J Orthod Dentofac Orthop 1979; 75:361-86.

13. Kim KR, Muhl ZF. Changes in dentoalveolar growth direction during and after cervical headgear treatment. Am J Orthod Dentofac Orthop 2001;119:522-30.

14. Kiijavainen M, Kiijavainen T, Hurmerinta K, Haavikko K. Orthopedic cervical headgear with an expanded inner bow in Class II correction. Angle Orthod 2000;70:317-25. 
15. Kloehn SJ. Guiding alveolar growth and eruption of teeth to reduce treatment time and produce a more balanced denture and face. Angle Orthod 1947;17:10-33.

16. Kuntz M, Turlot JC, Hildwein M. Le plan d'occlusion en classe I et en classe II: ses relations avec les variables cranio-faciales. Orthod Fr 1988;59:383-93.

17. Langlade M. Diagnostic orthodontique. Paris: Maloine, 1981:768 p.

18. Lejoyeux E. Les techniques des superpositions en céphalométrie. Encycl Med Chir, Odontologie, 1988;23-455-E-30, 6 p.

19. Lima Filho RM, Lima A, de Oliveira Ruellas AC. Longitudinal study of anteroposterior and vertical maxillary changes in skeletal class II patients treated with Kloehn cervical headgear. Angle Orthod 2003;73:187-93.

20. Lux CJ, Raeth O, Burden D, Conradt C, Komposch G. Sagittal and vertical growth of the jaws in Class II, division 1 and Class II, division 2 malocclusions during prepubertal and pubertal development. J Orofac Orthop 2004;65:290-311.

21. Mäntysaari R, Kantomaa T, Pirttiniemi P, Pykalainen A. The effects of early headgear treatment on dental arches and craniofacial morphology: a report of a 2 years randomized study. Eur J Orthod 2004;26:59- 64.

22. McNamara JA Jr, Peterson JE Jr, Alexander RG. Three-dimensional diagnosis and management of class II malocclusion in the mixed dentition. Sem Orthod 1996;2:114-37.

23. Melsen B. Effects of cervical anchorage during and after treatment: an implant study. Am J Orthod Dentofac Orthop 1978;73:526-40.

24. Pavlick CT Jr. Cervical headgear usage and the bioprogressive orthodontic philosophy. Sem Orthod 1998;4:219-30.

25. Phan XL, Schneider BJ, Sadowsky C, BeGole EA. Effects of orthodontic treatment on mandibular rotation and displacement in Angle Class II, division 1 malocclusions. Angle Orthod 2004;74:174-83.

26. Philippe, J. Les premières applications des forces extra-buccales en orthodontie. Rev Orthop Dento Faciale 1992;26:215-8.

27. Piva LM, Brito HHA, Leite HR, O'Reilly M. Effects of cervical headgear and fixed appliances on the space available for maxillary second molars. Am J Orthod Dentofac Orthop 2005;128:366-71.

28. Poulton DR. A three-year survey of class II malocclusions with and without headgear therapy. Angle Orthod 1964;34:181-93.

29. Ramos DS, de Lima EM. A longitudinal evaluation of the skeletal profile of treated and untreated class II individuals. Angle Orthod 2005;75:47-53.

30. Ricketts RM. The influence of orthodontic treatment on facial growth and development. Angle Orthod 1960;30:103-33.

31. Riolo ML, Moyers RE, McNamara JA Jr. et al. An atlas of craniofacial growth. University of Michigan, Ann Arbor (MI, USA): The Center for Human Growth and Development, 1971: 482 p.

32. Sauer GJR, Kuftinec MM. Cervera headgear. J Clin Orthod 1981;15:351-56.

33. Ülger G, Arun T, Sayinsu K, Isik F. The role of cervical headgear and lower utility arch in control of the vertical dimension. Am J Orthod Dentofac Orthop 2006;130:492-501.

34. Worms FW, Isaacson RJ, Speidel TM. A concept and classification of centers of rotation and extraoral force systems. Angle Orthod 1973;43:384-401.

35. You ZH, Fishman LS, Rosenblum RE, Subtelny JD. Dentoalveolar changes related to mandibular forward growth in untreated Class II persons. Am J Orthod Dentofac Orthop 2001;120:598-607. 